\title{
A diversidade cultural presente nos vídeos em saúde
}

Alice Ferry de Moraes ${ }^{1}$

MORAES, A.F. Cultural diversity in health-related videos. Interface - Comunic., Saúde, Educ., v.12, n.27, p.811-22, out./dez. 2008.

Videos are increasingly used as informational support in health-related social intervention actions. The objective of this paper was to become acquainted with the cultural elements in healthrelated videos, since they are information transfer facilitators. Studies on the use of health-related information in Brazil, the strength of images in individuals' cognition process and the need to put conveyed information into context served as the basis for analyzing the finalists among videos at the Third HealthRelated Video Show, promoted by the Oswaldo Cruz Foundation (Fiocruz) and held in Rio de Janeiro in 1998. By observing some of the technical data on these videos, it was possible to identify the cultural setting within which they were produced. The cultural diversity present in communication actions within all spheres, including health promotion and disease prevention, is an essential element for social progress.

Key words: Communication. Videos. Health. Culture.
Os vídeos, cada vez mais, são utilizados como suportes informacionais nas ações de intervenção social na área da saúde. Conhecer os elementos culturais existentes nos vídeos em saúde foi o objetivo deste trabalho, pois eles são facilitadores da transferência da informação. Estudos sobre o uso da informação em saúde no país, a força das imagens no processo cognitivo dos indivíduos e a necessidade de contextualização das informações repassadas serviram de base para a análise dos vídeos finalistas da III Mostra de Vídeos em Saúde, promovida pela Fundação Oswaldo Cruz (Fiocruz) e realizada no Rio de Janeiro, em 1998. Com base na observação de alguns dados das fichas técnicas desses vídeos, foi possível identificar o meio cultural no qual eles foram produzidos. A diversidade cultural presente nas ações comunicacionais em todos os âmbitos, inclusive na promoção da saúde e na prevenção de doenças, é um elemento essencial para o progresso social.

Palavras-chave: Comunicação. Vídeos. Saúde. Cultura.
1 Bibliotecária e jornalista. Laboratório de Comunicação e Saúde, Instituto de Comunicação e Informação Científica e

Tecnológica em Saúde, Fundação Oswaldo Cruz. Av. Brasil, 4036, sala 709. Rio de Janeiro, RJ ferry@cict.fiocruz.br 


\section{Introdução}

A multiplicidade de abordagens e a pluralidade de linguagens e gêneros, frutos da diversidade cultural, despertaram interesses e estimularam um estudo do uso de imagem em movimento na área da saúde no Brasil a partir de nossa participação no júri da III Mostra Nacional de Vídeos em Saúde, promovida pela Fundação Oswaldo Cruz (Fiocruz), e realizada, em 1998, no Rio de Janeiro.

A escolha dos vídeos de intervenção social a serem aqui abordados teve uma relação direta com sua atuação mais próxima à população mais carente de nosso país. Os vídeos analisados foram os produzidos de maneira a intervir socialmente, ao integrar ações de prevenção de doenças e promoção da saúde, por meio da mudança de comportamento dos indivíduos com base nas informações transferidas.

A hipótese apontada por este trabalho é a de que as informações, quando contextualizadas, trazem sucesso à ação de informar. Sendo assim, o objetivo desta pesquisa foi identificar os elementos culturais existentes nos vídeos finalistas da III Mostra Nacional de Vídeos em Saúde e estimular, por meio de argumentações teóricas, a contextualização das informações veiculadas nesses suportes informacionais.

O primeiro passo foi procurar conhecer como a informação em saúde expandiu-se e repercutiu no Brasil.

Saber como a imagem atua no processo cognitivo das pessoas foi a segunda preocupação deste trabalho. O vídeo, objeto deste estudo, é constituído por imagens em movimento (forma) e informações em saúde (conteúdo).

A transferência da informação, tal como foi conceituada neste texto, se relaciona com a visão cognitivista da Ciência da Informação, na medida em que estuda o processo informacional que tem por objetivo mudar o comportamento dos seus usuários, aqui representados pelos espectadores dos vídeos.

A necessidade de observância dos aspectos culturais dos grupos, para os quais são repassadas as informações em saúde, cresce com a constatação da inoperância de alguns vídeos que, apesar da sedução exercida por suas imagens, oferecem pouca informação ou informação sem adequação aos seus potenciais espectadores.

Qualquer que tenha sido o aspecto das imagens em movimento aqui abordadas, pode ser verificada a sua importância no uso de transferência da informação, seja pelo modo de representar a realidade, pela facilidade de compreensão dos conteúdos nelas contidos, ou, ainda, pela sua aceitação da estrutura cognitiva do indivíduo e sua difusão no ambiente social. Enfim, as imagens em movimento, com sua complexidade, despertam interesses de diversas áreas do conhecimento e da sociedade.

\section{Informação em saúde}

A informação em saúde foi instituída como instrumento de saúde pública desde o início do século XX. No Brasil, a adoção de técnicas de propaganda em saúde intensificou-se em 1920, com a criação do Departamento Nacional de Saúde Pública que tinha, entre outras atribuições, a de incentivar a educação sanitária. Na década seguinte, o rádio e o cinema tornaram-se instrumentos de campanhas de saúde, assim como da política. Inicia-se, dessa forma, a utilização das imagens em movimento na difusão de informações em saúde.

Por volta dos anos 1960, com o sanitarismo, foram feitas pesquisas, segundo Rodrigues (1967 apud Pitta, 1995), para identificar crendices e superstições, assim como saberes sobre: meios de transmissão de doenças, costumes, líderes locais, meios de comunicação disponíveis, e o papel das escolas e das igrejas na questão da saúde. A partir daí, estratégias de persuasão passaram a ser utilizadas com o objetivo de "substituir o espírito de relutância" dos indivíduos em "aceitar cumprir as providências recomendadas pelas autoridades sanitárias, conforme o ideário da tradicional educação sanitária" (Rodrigues, 1967 apud Pitta, 1995, p.241).

Na década de 1970, ainda de acordo com Rodrigues, na segunda edição de seu livro (1979 apud Pitta, 1995, p.241), " a administração sanitária passa a incorporar inovações como 'ajuste da linguagem' à 'população-alvo' uma forma de conferir mais eficácia aos procedimentos de transferência de informações a indivíduos ou grupos sociais". 
Apesar de todos os esforços empregados pelas instituições e profissionais da saúde na comunicação de informações sobre a área, estudos desenvolvidos por instituições governamentais e não governamentais do campo da saúde e da agricultura mostraram que parte dos indivíduos ainda não percebia o conteúdo das mensagens recebidas. Uma das causas identificadas foi a tensão criada entre as "noções" de saúde, recebidas por esses indivíduos, e a vida cotidiana (Pitta, 1995).

No final da década de 1980 houve uma politização do acesso à saúde, visto como um direito civil. Foram realizadas, na VIII Conferência Nacional de Saúde, diversas discussões sobre práticas comunicacionais como um pressuposto do direito à saúde por parte da população brasileira, incluindo "educação e informação plenas, participação na organização, gestão e controle dos serviços e ações de saúde; direito à liberdade, à livre organização e expressão" (Conferência Nacional de Saúde, 1986, p.386).

Ainda hoje, levar informação sobre saúde para comunidades carentes de tudo é uma tarefa nobre. Utilizar o vídeo, uma tecnologia bem atual, por suas transformações possíveis (CD-ROM e DVD) é fascinante. Ele torna a informação onipresente (TV, computador, telão, telinha) e universal. As imagens chegam, sem discriminações, a todos, letrados e não letrados. As informações nele contidas são polivalentes. Ensinam, discutem, divulgam informações, influenciam, dão voz e vez a pessoas, e salvam vidas. Trabalhar com informação em saúde é trabalhar para a promoção da inclusão social.

O interesse cada vez maior pelo tema saúde em nossa sociedade traz consigo a produção de estudos e pesquisas, nas áreas das ciências sociais, sobre ele, assim como a produção de vídeos.

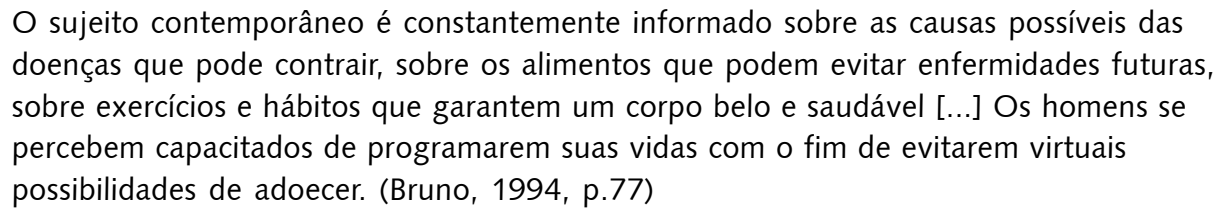

Os vídeos de intervenção social, objeto deste trabalho, procuram usar uma linguagem adequada a seu público para, subseqüentemente, desencadear ações ou mudanças de comportamento de seu público. A contextualização informacional servirá de instrumentos de adaptação, cada vez maior, dos discursos desses vídeos que, muitas vezes, englobam mais de uma fala no seu interior. Foi o que verificou Rondelli (1995), com base na análise de vídeos de programas de entrevista sobre saúde. Esses vídeos apresentam três tipos de discursos: o leigo (por meio de depoimentos de pessoas comuns, facilitando a identificação do espectador com esse relato subjetivado); o especialista (por meio de depoimentos de médicos que, com base no campo científico, tentam levar, ao espectador, informações sobre essa área, utilizando uma fala nem sempre simples, mas que, comumente, emprega metáforas para se fazer entender); o midiático (por intermédio da fala de um profissional - jornalista, educador etc. - que faz a mediação entre os depoimentos leigo e especialista, podendo ser o fio condutor para a compreensão do tema).

De acordo com o Boletin sobre Reducción Desigualdades en Salud, um estudo publicado pela Organização Pan-Americana de Saúde - OPAS (2001) demonstrou que os integrantes das populações de baixa renda não identificavam sua má saúde ou enfermidades e, conseqüentemente, não recorriam aos centros de saúde, mesmo com assistência médica gratuita. Sendo assim, consideram-se necessários programas de educação em saúde pública para levar, até essas pessoas, informações úteis sobre diversos males que poderiam acometê-las. Para esses casos, o vídeo é um veículo adequado.

Outro exemplo a ser observado é também recente. Por ocasião da primeira epidemia de dengue, no Rio de Janeiro, em entrevista a Magalhães, a bióloga cubana Montero Lago (2002) afirmou que, nos países mais carentes, muitos habitantes não têm formação educacional suficiente para entender as informações disseminadas nas campanhas de saúde, por mais que elas sejam repassadas de maneira maciça. Seriam necessários, segundo ela, meios facilitadores para a compreensão das informações disseminadas. Mais uma vez, a imagem em movimento foi considerada um instrumento apropriado, como foi possível observar nas campanhas sobre a dengue no Brasil, suplantando os resultados obtidos pela divulgação via panfletos e cartilhas. 
Este trabalho, no entanto, ressalta que, por vezes, alguns problemas ocorrem pela não observância de certas ações por parte de alguns promotores das campanhas de saúde, ou seja, ocorrem porque, ao se transferirem informações, eles não levam em consideração o contexto dos indivíduos que as receberão, não importando o veículo utilizado. Sendo assim, fica difícil a obtenção de mudanças na maneira de agir, por parte dos usuários da informação, para melhorar a saúde.

A mudança no comportamento das pessoas tem diversas origens. As ciências sociais afirmam que 0 que gera um tipo de comportamento, na maior parte das vezes, é produzido por elementos fora do indivíduo. Por exemplo: a antropologia vê a cultura como responsável pelo comportamento humano; a ciência política considera a estrutura de governo e a forma de exercício do poder como formadoras do comportamento humano; a sociologia observa a organização social e sua influência no comportamento dos elementos de uma sociedade. Essas ciências contribuem para o entendimento da ação humana.

O comportamento das pessoas pode ser alterado pelo discurso, cuja construção de significados está na formação, na narração que, em tempos idos, tiveram expressão pictográfica e oral, depois manuscrita e impressa, e, hoje, junto às diversas expressões, utilizam a imagem transmitida, entre outras formas, pelo vídeo.

As teorias de persuasão reexaminam o papel da cultura e da organização social que, por vezes, são obstáculos para mudanças de comportamento. Campanhas informativas obtiveram resistência comportamental devido a práticas culturais institucionalizadas. Rogers (1995) relata o caso de uma agente de saúde tentando persuadir os membros de uma tribo de índios no Peru, vítimas do cólera, a ferverem a água para não ficarem doentes. Na tribo, por tradição cultural, somente as pessoas doentes bebiam água fervida, e não as que estavam com saúde. Quando a agente fez uma explanação sobre os micróbios na água não fervida, os índios consideraram que o tamanho dos micróbios impossibilitaria um ataque a eles, que eram infinitamente maiores, e resolveram não acatar as sugestões da agente de saúde.

\section{Imagens}

A força comunicacional das imagens é reconhecida por todos. Elas foram utilizadas nos primeiros registros informacionais produzidos pelo homem quando, ainda nas cavernas, desenhos tentavam reproduzir ações do dia-a-dia como, por exemplo, caçadas, perseguições a animais.

Manguel (2001) declara que as palavras de um livro só permanecem, de forma parcial, em nossa memória, enquanto uma imagem pode ficar, de forma integral, para sempre.

Bosi (1993) relata que os psicólogos da percepção são unânimes em afirmar que a maioria absoluta das informações, obtida pelo homem, vem por imagens. O homem de hoje é um ser predominantemente visual. Alguns chegam à exatidão do número: $80 \%$ dos estímulos seriam visuais. Para conhecer, diz Bosi (1993, p.67) "basta abrir bem os olhos em um espaço iluminado e acolher os levíssimos e agílimos ícones do mundo".

A força da imagem para transferir informação não está relacionada apenas à sua ação visual e textual, mas, também, à memória e ao imaginário social. Nossos sonhos são imagens, nossos pensamentos também. Ambos são frutos de nossa imaginação, ou seja, a ação de colocar em imagens desejos, medos, expectativas, conhecimento. No entanto, a imagem é identificada, por muitos, como o contrário da escrita. Por analogia, muitos atribuem a crise da leitura dos livros à sedução das tecnologias da imagem e, entre elas, a do vídeo.

A imagem oferece um tipo de "leitura". Essa "leitura" envolve três níveis, segundo Barthes (1990): o nível informativo, que corresponde ao nível da comunicação (reconheço a imagem, o que vejo); o nível simbólico, que corresponde ao nível da significação (a imagem evoca um simbolismo de fácil acepção), e o nível da significância, que corresponde à observação da razão analítica (apresenta algo que exige uma reflexão para seu entendimento).

Existem as imagens paradas (fotografias, ilustrações etc.) e as imagens em movimento (vídeos), sobre as quais nos detemos. Elas são assim chamadas porque registram cenas onde há movimentos tanto das personagens quanto dos demais elementos integrantes da cena visualizada. Além disso, o equipamento de registro de imagem e de som é utilizado com movimento próprio, aumentando ainda mais a percepção daquilo que é intenção do diretor mostrar. 
Elas se dirigem tanto ao espectador individual quanto ao coletivo, podendo, assim, ser utilizadas em espaço doméstico ou social. Há sempre uma intenção na realização de um vídeo, e seu valor vai depender do seu uso e de sua interpretação.

No Brasil, desde o final da década de 1930, o uso das imagens em movimento, tendo como suporte o filme, foi intensificado na disseminação de informações em saúde. Destacaram-se os filmes produzidos pelo Instituto Nacional do Cinema Educativo (Ince), criado, em 1936, pelo então Ministro da Educação e Saúde, Gustavo Capanema, e dirigido por Edgard Roquette Pinto.

Hoje, o cinema foi substituído, em grande parte, pela televisão e pelos vídeos na ação de divulgar ciência e saúde, sendo seus produtos reproduzidos pelos aparelhos de videocassete e pelos computadores, via internet.

A televisão, como o vídeo, pode oferecer suas imagens nos lares de cada espectador. A singularidade do vídeo está no fato de as imagens poderem ser interrompidas, repetidas, regravadas para serem vistas quando o espectador deseja ou precisa. Além disso, o vídeo pode ser transportado para qualquer lugar onde haja um aparelho reprodutor.

As representações empregadas na produção do vídeo em saúde são de diversos tipos e, entre elas, algumas são semelhantes às utilizadas pela programação da popular televisão, aproximando-o, ainda mais, de seu espectador; e não há distinção quanto à sua utilização, uma vez que o vídeo em saúde desperta interesse em pessoas de diferentes classes sociais ou níveis educacionais. A imagem seduz a todos e, sendo uma representação da realidade, ela traz consigo o encantamento dos registros em movimento e cores, envoltos em emoção.

$\mathrm{Na}$ área da saúde, existem diversos tipos de vídeo, destacando-se dois: os de campanha e os de intervenção social.

Os vídeos de campanhas de saúde, com duração de até um minuto e com elemento persuasivo destacado, assim como os vídeos de divulgação, com duração de 15 minutos em média, são, na maioria dos casos, produzidos pelo Ministério da Saúde (MS).

Os vídeos de intervenção social também são realizados pelo MS e/ou instituições de saúde, para grupos sociais específicos, com duração de 15 minutos em média e com elemento persuasivo. São os vídeos produzidos, por exemplo, com base em programas de saúde, para comunidades onde se desenvolvem ações de saúde para prevenção de doenças e promoção da saúde. Eles são considerados um instrumento de intervenção por sua utilização para conscientizar um grupo social a mudar o comportamento frente a um problema de saúde. A diferença entre esses vídeos e os de campanhas de saúde está na duração e na veiculação. Os vídeos de campanha têm apresentações repetidas na mídia, sobretudo, na televisão, enquanto os de intervenção têm grupo e local próprio para exibição.

Foi possível concluir que o uso da imagem para informar é, em si, um processo estratégico para transferir informações, devido ao fascínio exercido por ela sobre os indivíduos. Estratégia foi compreendida como a aplicação dos meios disponíveis ou exploração das condições favoráveis para se alcançarem objetivos específicos. O objetivo a ser alcançado era a transferência da informação.

\section{Transferência da informação}

Os vídeos foram analisados na sua função primordial, que era a de transferir informações, tema importante para a Ciência da Informação. Quando essa transferência se realiza, ela faz com que o usuário/espectador assimile a informação, que, por sua vez, trará mudanças a sua estrutura cognitiva e poderá desencadear ações, dentre as quais, a mudança de comportamento.

Confirmar a transferência da informação implica desenvolver pesquisa sobre recepção, o que não foi o objetivo deste trabalho. Sousa (2001) destacou que ainda não existem estudos suficientes sobre a recepção das informações veiculadas aos efeitos dos vídeos no comportamento de seu público, no que se refere a intervenções no campo da saúde. É necessário explorar o papel desse tipo de mídia, de maneira a torná-la um veículo fértil de informações, sem esquecer as críticas sobre seu papel na formação de opinião.

Para teóricos da visão cognitivista da Ciência da Informação, como Barreto (1996, p.6) "é [...] na transferência da informação que se revela a essência do fenômeno da informação". Quanto mais 
familiar nos parecer a informação, mais rapidamente acreditamos nela ou a aceitamos. Norton (2001), no entanto, considera que a informação pode: não afetar, alterar alguma coisa ou alterar significativamente o conhecimento de alguém.

Roberts (1976), por sua vez, afirma que a informação é adquirida no meio ambiente, nem sempre em formas estruturadas, ressaltando que os indivíduos já possuem seus próprios estoques de informações e uma série de atitudes associadas a eles. As informações são avaliadas, aceitas ou rejeitadas, relacionadas, manipuladas e, possivelmente, sofrem influência das variadas maneiras pelas quais são adquiridas.

Por vezes, a transferência da informação não ocorre por conta de barreiras. Wersig (1977), ao falar sobre o treinamento de usuários, aponta algumas dessas barreiras informacionais que são, na verdade, antíteses das estratégias. Dentre elas, citamos, por exemplo: a) barreira terminológica - produzida pelo emprego de terminologia fora do alcance daqueles que utilizarão a informação, e b) barreira de capacidade de leitura ou nível de entendimento - produzida pela inadequação da informação ao nível de entendimento de seu usuário em potencial.

Algumas dessas barreiras estão diretamente relacionadas à produção de informação por meio dos vídeos.

Capurro (1992, p.88) surpreende ao trabalhar sob a influência da retórica em suas pesquisas em Ciência da Informação. Para ele, "a informação é uma compreensão pragmática de um mundo comum, compartilhado". Assim sendo, mais importante do que querer saber "o que é informação", diz ele, é saber "para que é a informação". É preciso ressaltar a condição contextual da informação, isto é, sua dimensão histórica, cultural, econômica, política, que são essenciais para sua compreensão.

Complementando o que foi dito por Capurro, para Barreto (2000), o problema maior do produtor de informação está na heterogeneidade dos indivíduos e seus saberes. A transferência da informação deve levar em consideração as dimensões acima citadas, pois elas integram a cognição individual e coletiva.

Observa-se, também, a forte influência dos códigos de moral e ética, das religiões na credibilidade das fontes informacionais, e da utilização de uma linguagem clara para a conclusão do processo informacional com êxito.

A teoria sobre cognição coletiva de Pierre Lévy (1993) enfatiza as mudanças na estrutura do conhecimento no sujeito coletivo e dá destaque à relação homem-tecnologia. Para ele, os instrumentos da inteligência são: a linguagem, as ferramentas, as instituições e as regras sociais que, ao agirem, fornecem uma dimensão coletiva para a inteligência, concluindo, assim, que os seres humanos jamais pensaram sozinhos. Isso, até certo ponto, ressalta o uso dos vídeos como instrumento de transferência da informação em saúde.

Ainda com um sentido coletivo, mas numa abordagem diferenciada da de Lévy, Demo considera que a comunicação humana é mediada, sobretudo, pelos atos de fala, não apenas porque dela participam seres racionais e conscientes, mas também por outros motivos, tais como:

só se realiza o fenômeno da compreensão de significados, quando existe, entre quem fala e quem ouve, o background da tradição e do mundo comum da vida, cuja base de funcionamento não é a reflexão racional consciente; a comunicação não se restringe à mera transmissão de informação, mas inclui a capacidade de interpretação mútua, que supõe a possibilidade de, pelo menos, algum consenso social; a comunicação provoca no ouvinte o compromisso de compreender, que desde logo não pode ser apenas objeto de manipulação; os atos da fala, como ação social típica, implicam alguma forma de participação do ouvinte, pelo menos ao nível de estar engajado num mundo comum de significações e atuações. (Demo, 2001, p.186)

De um modo geral, foi possível constatar que o valor da informação está localizado em uma realidade específica e potencializado por sua transferência. O conceito desse valor é relativo e próprio de cada indivíduo e depende de: a) preferência por uma informação em detrimento de outra; b) competência cognitiva para compreender as informações e estabelecer possível comparação. 
Ao abordar a questão sobre o valor da informação, González de Gómez $(1999$, p.9) o considera fruto de uma seleção individual e social, que pode incluir fatores de caráter emocional, cultural, prático e gnosiológico.

\section{Contextualização}

A comunicação simbólica entre os indivíduos e o relacionamento deles com a natureza formam, no tempo (história) e no espaço (territórios específicos), identidades culturais. A tecnologia, hoje, desempenha um papel de interação entre identidades biológicas e culturais dos indivíduos em seu ambiente social e natural. Essa interação, por ser um processo social, é estruturada historicamente. As tecnologias acabam por influir na formação da personalidade dos indivíduos e integram, simbolicamente, uma busca da satisfação de necessidades e desejos humanos.

A sociologia esclarece os fundamentos do conhecimento na vida cotidiana, ou seja, as significações que constroem o mundo intersubjetivo do senso comum e a consciência dos indivíduos.

A consciência é capaz de mover-se por meio de diferentes esferas da realidade. Ela é capaz de identificar a diferença entre as pessoas do cotidiano, no trabalho, e as pessoas presentes nos sonhos. Segundo Berger e Luckmann (1993), entre as múltiplas realidades, há uma que se apresenta como a principal: a da vida cotidiana. Ela é ordenada por fenômenos previamente dispostos em padrões aparentemente independentes da forma de apreensão. É como se os objetos que a integram existissem previamente antes da entrada do indivíduo em cena. O tempo da realidade diária é contínuo e finito. Toda a existência do indivíduo no mundo é ordenada pelo tempo. O tempo já existia antes de ele nascer e continuará a existir depois que ele morrer. A estrutura temporal fornece historicidade, determinando a situação do indivíduo no mundo da vida cotidiana e impondo-se na sua biografia.

Outras realidades, como as brincadeiras de criança, o teatro, a religião, o vídeo, aparecem como campos com limites de significação, exceções dentro da realidade dominante (vida cotidiana) que têm diversos significados e experiências ilimitadas. A realidade dominante envolve as outras realidades, fazendo com que o indivíduo retorne a ela.

Um processo comunicacional diferenciado, segundo Martino (2001), pressupõe o convívio de diversos grupos, com diferentes tipos de ação, aos quais o indivíduo se associa, circunstancialmente, ao longo de sua vida. Tal como a consciência, envolve múltiplas relações, ou seja: de trabalho, de escola, de vizinhança, de amizade, de família. Sendo assim, os vínculos que o indivíduo constrói são variados, espontâneos e adaptados aos diversos grupos. Em cada um deles, haverá um processo comunicacional diferenciado, proporcionando vínculos sociais, com linguagens, ritos e regras próprios. Esses processos podem ser iguais, semelhantes ou bem diferentes entre si.

As informações, veiculadas pelas mídias, não são indiferentes ao atendimento das crenças e desejos da sua audiência. Se assim não for, não há possibilidade de sucesso e de continuação do ato de informar. É real que as mídias possam também, com certos limites, reconstruir ou influenciar essas mesmas crenças e desejos do seu público. Portanto, o entendimento dessa situação é fundamental. Trata-se de um sistema integrado de mão dupla, onde cada parte desenvolve seu papel, interagindo de modo dialético, segundo Lopes (2001).

A vida cotidiana pode ter diferentes graus de aproximação e distância, de espaço e tempo. Em termos de espaço, a zona da vida cotidiana mais próxima é a acessível à manipulação corporal. A atenção a este mundo é, sobretudo, determinada pelas ações passadas, presentes ou futuras. $O$ interesse por zonas distantes é menos intenso e menos urgente.

Nos dias de hoje, a realidade referencial, para muitos, é virtual, uma espécie de telerrealidade. Existe uma variedade de técnicas e tecnologias que simulam a realidade física ou histórica. A sensação do virtual é igual à tomada de consciência do indivíduo no mundo real. O vídeo é uma vida paralela, construída por meio de uma relação afetiva, com base em uma identificação do espectador com o conteúdo do vídeo.

O virtual é diferente do real. O real tecnologicamente é igual ao virtual e, de algum modo, é inacabado. Mas o real, em si, não existe porque ele é fruto da objetividade, de um grau de realidade 
determinada pela consciência. A consciência é uma operação informacional, um mundo análogo, uma metáfora da interiorização.

Na nossa sociedade, o conceito de cidadania é ampliado, proporcionando, por meio do direito à informação, a criação de novos discursos com significância mais dirigida para as causas sociais. $O$ indivíduo está ligado às suas necessidades biológicas, mas também às suas necessidades sociais, frutos da estrutura de um ambiente social. Como exemplos desse tipo de necessidades, podem ser citados: as de realização, de aprovação social, de nutrição, de divertimento, de ordem, de cobiça, de respeito.

Tanto a intervenção social quanto a intervenção informacional e comunicacional lidam com três questões da vida social: saber, poder e ética. Elas nos fazem pensar em diversos discursos (incluindo o imagético, objeto deste trabalho), nas relações de poder que eles trazem consigo e nos seus efeitos na vida social.

O discurso científico, presente nos vídeos em saúde, é um discurso do saber, tido como competente (Chauí, 1982) e como uma forma de poder. O vídeo como elemento de comunicação e informação ganha respeitabilidade no espaço da opinião pública por meio da noção de competência, diretamente relacionada a quem comunica e informa.

Ressaltamos, no entanto, que a percepção do espectador do vídeo, baseada no seu saber, nos seus sentimentos e nas suas crenças, vai estar ligada à sua vida cotidiana, que, por sua vez, relaciona-se com sua classe social, época e cultura.

Reconhecer o mundo visual em uma imagem pode ser útil, além de proporcionar, também, um prazer específico (Aumont, 1999).

O poder é exercido por meio das relações sociais mediadas por comunicação de informações. Segundo Frohmann (1995), o domínio sobre a informação, quando alcançado, é mantido por grupos específicos, que o utilizam para a dominação. Mas ainda assim, algumas informações sofrem resistência ao serem comunicadas a determinados grupos e em determinadas ocasiões.

Uma atitude informacional ética da informação está diretamente relacionada à observação do estilo de vida dos usuários/espectadores. A transferência de informações em saúde deve ocorrer por meio de uma linguagem simples e acessível.

\section{Coleta e análise dos dados}

Com base em dados das fichas técnicas das produções selecionadas como finalistas, na III Mostra Nacional de Vídeos em Saúde, e nas teorias apresentadas neste trabalho, foram realizadas análises de cada tipo de dado dos vídeos que servia como identificador da diversidade cultural.

Foram vistos os títulos dos vídeos, os seus produtores, as regiões onde foram produzidos os vídeos, os assuntos abordados e outros detalhes técnicos.

Entre os cento e vinte vídeos enviados de todas as partes do Brasil, foram selecionados, como finalistas, sessenta e um com temas sobre saúde, e outros relativos a problemas sociais, de destaque na nossa sociedade, que acabam por tornarem-se questões de saúde, como, por exemplo: mendicância, lixo, saneamento básico, direitos humanos etc.

Os títulos eram, em sua maioria, claros e diretos, ou seja, eles guardavam sua característica informativa ao exporem o conteúdo dos vídeos. A persuasão pôde ser encontrada no título, fazendo menção ao "cuide-se", por exemplo, no título do vídeo Antes que seja tarde. O humor também foi um ingrediente na construção dos títulos como, por exemplo, O peso de estar acima do peso e Tabagismo, tô fora. Houve também os títulos que não ofereceram, de imediato, o seu conteúdo, como, por exemplo, Prevenção e Um bom conselho.

Coube às organizações não governamentais a responsabilidade pela produção de 16 vídeos finalistas, seguidas pelas universidades públicas, com 13 vídeos. Instituições diversas dos governos federal, estadual e municipal produziram os demais vídeos finalistas, com exceção de seis deles que tiveram produtores independentes. A questão da saúde, embora importante, não seduz ainda esses produtores, talvez por não auferir lucros. Coube, portanto, ao Estado, a incumbência maior de fornecer informações sobre saúde. 
Doze estados brasileiros e o Distrito Federal tiveram vídeos entre os finalistas da III Mostra. O estado com mais vídeos finalistas foi Pernambuco, com 13 vídeos. Em seguida, veio São Paulo, com 11. Rio de Janeiro e o Distrito Federal apresentaram nove vídeos cada um na final. Minas Gerais, Bahia, Paraná, Rio Grande do Sul e Santa Catarina foram para a final com três vídeos cada. Alagoas, Espírito Santo, Goiás e Paraíba tiveram um vídeo cada como seus representantes entre os finalistas.

O desenvolvimento econômico e tecnológico, mas também uma situação oposta foram elementos motivadores para a produção de vídeos em saúde. Explicando melhor: por um lado, regiões que possuem todos os tipos de recursos para a produção desses vídeos, possuem também problemas de saúde oriundos da superpopulação, da vida estressante das grandes cidades etc. Esses temas estiveram presentes na Mostra analisada. Por outro lado, regiões onde existe carência de recursos técnicos e econômicos, a produção de vídeos foi estimulada pela premência de informação transferida pelos vídeos, sobretudo nas áreas de baixa escolaridade e problemas de saúde provocados pela fome, pela seca, pela falta de saneamento básico, etc.

Uma análise por regiões geográficas do Brasil mostrou que a região Norte não teve nenhum vídeo na Mostra. A região Sudeste (RJ, SP, ES, MG) teve 24 vídeos, possivelmente por ser uma região com muitos recursos econômicos e técnicos. A região Nordeste (PE, BA, AL, PB) surpreendeu com 18 produções, fato muito auspicioso uma vez que essa região, devido a carências financeiras e educacionais, necessita de vídeos em saúde para a prevenção de doenças e promoção da saúde. A região Centro-Oeste (GO e DF) apresentou dez vídeos, com peso forte na produção advinda do Distrito Federal, onde se localiza o MS. A região Sul (PR, SC, RS) foi representada por nove vídeos.

Os 61 vídeos finalistas abordaram 48 diferentes assuntos, sendo as doenças, propriamente ditas, os temas mais recorrentes, seguidas pelas questões de saúde pública em geral. Os problemas de saúde da mulher, também, foram abordados com alguma freqüência.

Por meio de uma análise sobre os temas, vistos de forma individual, observou-se que o tema AIDS foi o privilegiado, com seis vídeos, além de um vídeo sobre doenças sexualmente transmissíveis (DST), que incluía a AIDS, mal de abrangência universal que, por esse motivo, sempre teve financiamento farto para campanhas de prevenção.

Em seguida, o tema saúde pública apresentou três vídeos. Outros temas tiveram destaque, como: aborto, saúde mental, gravidez na adolescência, práticas populares de saúde, alcoolismo e saúde em geral, que apresentaram, cada um, dois vídeos entre os selecionados.

Os vídeos selecionados na III Mostra, de um modo geral, tiveram, como característica, a apresentação de temas de forma educativa e sem reprimendas. Os depoimentos de vítimas de doenças eram contundentes e até emocionantes, mas sem "apelações" de comunicação.

A música, em muitos vídeos, foi um elemento com forte presença para a contextualização (músicas regionais) e o despertar de emoções, podendo ser considerada, em determinados casos, uma estratégia informacional.

As informações, na maioria dos casos, foram repassadas de maneira objetiva, em função do curto tempo de duração que os vídeos têm.

O humor foi um elemento muito presente, por ser uma característica do povo brasileiro, mesmo quando diante de adversidades.

O trabalho com atores funcionou muito bem para alguns casos. Em outros, o melhor mesmo foi a utilização de entrevistas, depoimentos ou declarações espontâneas ou estruturadas.

Assistir a esses vídeos foi uma experiência única porque eles englobavam informações sobre doenças e saúde, sobre grupos sociais, sobre experiências de vida, apresentando-as, quase sempre, de maneira clara e com arte; porque a utilização da imagem tem muita proximidade com o encantamento e a sedução, mesmo quando o exposto não tenha um aspecto positivo, como é o caso das doenças.

\section{Considerações finais}

Ficou evidente que a construção de significados, relacionada à cultura e ao contexto social, foi utilizada na formação dos discursos e narrativas dos vídeos como instrumento de grande uso e penetração na 
nossa sociedade. Ficou claro que falar em linguagem, seja ela imagética ou não, é falar de estruturas sociais e, conseqüentemente, comunicacionais, de transmissão de informação. Elas foram vistas sob a forma de elementos políticos, históricos, culturais produzidos pelo desenvolvimento da sociedade. A questão informacional, que envolve a saúde dos indivíduos, tem um forte caráter democrático, na medida em que esses indivíduos - que não tinham as informações sobre o que acontece em seus organismos, seus corpos - possam compreender, refletir e tomar decisões sobre sua saúde. Em qualquer circunstância, sempre deverá existir uma escolha ética sobre que informação precisará ser transferida e para quem.

O interesse e a necessidade foram vistos como elementos balizadores desse processo informacional. Uma informação, se não for desejada ou não se mostrar adequada, dificilmente conseguirá chamar a atenção de alguém.

As preocupações informacionais apresentadas por este trabalho existem porque, infelizmente, no Brasil, há um percentual significativo da população que vive abaixo da linha da pobreza. Dela fazem parte indivíduos que não têm acesso a quase nada. Essa parte da população está exposta a diversos problemas de saúde decorrentes da fome e das condições de vida. A fome traz consigo, entre outros problemas, o atraso no desenvolvimento físico e cognitivo.

Em se tratando do planejamento de campanhas de prevenção de doenças ou de promoção da saúde, qualquer coisa que facilite o alcance de seus objetivos deve ser vista com bons olhos, pois em foco estão a saúde e o bem-estar da população.

\section{Referências}

AUMONT, J. A imagem. São Paulo: Papirus, 1999.

BARRETO, A.A. A eficiência técnica e econômica e a viabilidade de produtos e serviços de informação. Ci. Inf., v.25, n.3, 1996. Disponível em: <http://revista.ibict.br/ index.php/ciinf>. Acesso em: 15 jun. 2000.

BARTHES, R. O óbvio e o obtuso: ensaios críticos. Rio de Janeiro: Nova Fronteira, 1990.

BERGER, P.L.; LUCKMANN, T. Os fundamentos do conhecimento na vida cotidiana. In: A construção social da realidade. Tratado de sociologia do conhecimento. 10.ed. Petrópolis: Vozes, 1993. p.35-68.

BOSI, A. Fenomenologia do olhar. In: O olhar. São Paulo: Companhia das Letras, 1993. p.65-87.

BRUNO, F. Dietética: a saúde na mídia. Eco, v.1, n.5, p.69-82, 1994.

CAPURRO, R. Foundations of Information Science. Review and perspectives. In: VAKKARI, P.; CRONIN, B. (Eds.). Conceptions of Library and Information Science. Historical, empirical and theoretical perspectives. London: Taylor Graham, 1992. p.8298.

CHAUÍ, M. Cultura e democracia: o discurso competente e outras falas. São Paulo: Moderna, 1982.

CONFERÊNCIA NACIONAL DE SAÚDE, 8. 1986, Brasília. Anais... Brasília: Ministério da Saúde, 1986.

DEMO, P. Conhecimento moderno: sobre ética e intervenção do conhecimento. 4.ed. Petrópolis: Vozes, 2001. 
FROHMANN, B. Taking information policy beyond Information Science applying the actor netwok theory. In: ANNUAL CONFERENCE OF CANADIAN ASSOCIATION FOR INFORMATION SCIENCE, 23., 1995, Edmonton. Proceedings ... Alberta, 1995.

GONZALEZ DE GÓMEZ, M.N. O caráter seletivo das ações de informação. Informare, v.5, n.2, p.7-30, 1999.

LÉVY, P. As tecnologias da inteligência: o futuro do pensamento na era da informática. Rio de Janeiro: Ed. 34, 1993.

LOPES, L.C. Representação e significação nos fenômenos comunicacionais. Ciberlegenda, n.5, 2001. Disponível em: <http://www.uff.br/mestcii/lclop5.htm>. Acesso em: 19 ago. 2001.

MANGUEL, A. Lendo imagens: uma história de amor e ódio. São Paulo: Companhia das Letras, 2001.

MARTINO, L.C. Interdisciplinaridade e objeto de estudo da comunicação. In: MARTINO, L.C.; FRANÇA, V.V. (Orgs.). Teorias da comunicação: conceitos, escolas e tendências. Petrópolis: Vozes, 2001. p.27-38.

MONTERO LAGO, G. Prevenção é para o ano todo. Jornal do Brasil, 10 mar. 2002. Primeiro Caderno, p.13. Entrevista concedida a Luiz Ernesto Magalhães.

NORTON, M.J. Communications. In: Introduction concepts in Information Science. Medford: Information Today, 2001. p.39-50. (ASIS monograph series).

ORGANIZAÇÃO PAN-AMERICANA DE SAÚDE. Boletín sobre reducción de desigualdades en salud [mensagem institucional]. Enviado a partir de: <equidad@lisserv.paho.org> em 14 jun. 2001.

PITTA, A.M.R. Interrogando os campos da saúde e da comunicação: notas para o debate. In:___ (Org.). Saúde \& comunicação: visibilidades e silêncios. São Paulo: Hucitec; Rio de Janeiro: Abrasco, 1995. p.239-66.

ROBERTS, N. Social consideration towards a definition of Information Science. J. Doc., v.32, n.4, p.249-57, 1976.

ROGERS, E. Diffusion of innovations. New York: The Free Press, 1995.

RONDELLI, E. Mídia e saúde: os discursos se entrelaçam. In: PITTA, A.M.R. (Org.). Saúde \& comunicação: visibilidades e silêncios. São Paulo: Hucitec; Rio de Janeiro: Abrasco, 1995. p.38-47.

SOUSA, I.C.F. Sucesso e fracasso numa experiência de educação em saúde. Rev. Educ. Ens. - USF, v.4, n.1, p.39-44, 2001.

WERSIG, G. Information consciousness and information propaganda. Common features of training of information specialists. In: FEDERATION FOR INFORMATION AND DOCUMENTATION. COMMITTEE ON EDUCATION AND TRAINING TECHNICAL MEETING, 1976, Madrid. Occasional paper 3... Frankfurt am Main: Deutsche Gesellschaft für Dokumentation, 1977. 
MORAES, A.F. La diversidad cultural presente en los vídeos sobre salud. Interface Comunic., Saúde, Educ., v.12, n.27, p.811-22, out./dez. 2008.

Los vídeos, cada vez más, se utilizan como soportes informacionales en las acciones de intervención social en el área de la salud. Conocer los elementos culturales existentes en los vídeos sobre salud ha sido el objeto de este trabajo, ya que son facilitadores de la transferencia de la información. Estudios sobre le uso de la información, a fuerza de imágenes en el proceso cognitivo de los individuos y la necesidad de contextualización de las informaciones transmitidas han servido de base para el análisis de los vídeos finalistas de la III Muestra de Vídeos en Salud organizada por la Fundación Oswaldo Cruz (Fiocruz) y realizada en Rio de Janeiro, Brasil, en 1998. A partir de la observación de algunos datos de las correspondientes fichas técnicas, ha sido posible identificar el medio cultural en el que se produjeron. La diversidad cultural presente en las acciones de comunicación constituyen elemento esencial para el progreso social.

Palabras clave: Comunicación. Vídeos. Salud. Cultura.

Recebido em 05/04/07. Aprovado em 25/04/08. 